\title{
Study on Public Speech and Children Language Teaching From the Perspective of Emotion
}

\author{
ZHANG Shu-ya \\ Wuhan University of Technology, Wuhan, China
}

\begin{abstract}
With the development of Affective Neuroscience, people are increasingly concerned about the relationship between emotion and cognition. Language, as a means of communicating and studying in human society, is one of the vital cognitive activities of human beings. Therefore, the relationship between emotion and language processing is valued by researchers all over the world. According to the Interaction Theory, this paper uses observational method to observe the listeners' reactions to Ivanka’s speech, including the applause, the yell, face expression, and action, to study the influence of emotion on language processing and language learning so as to study children language teaching methods which can motivate students' interests in learning and improve their language learning efficiency by applying the methods of public speech to the academic speech. The study about Ivanka's speech is mainly from two aspects: (1) the influence of emotional information in language on language learning, including emotional words, sentences, and speeches; (2) the influence of external emotional background on language learning, including the emotional intonation, speech rhythm, and context. What's more, the author spends one year in studying the effect of applying the public speech methods on children language learning. The author finds that applying the speech methods of public speech to academic speech has vital influence on motivating children's learning interests and improving their learning efficiency.
\end{abstract}

Keywords: emotion, public speech, children language teaching

\section{Introduction}

Emotion, a vital part of the motivational mechanism in people's psychological activities, accompanies people all the time. With the development of Affective Neuroscience, researches are increasingly concerned about the relationship between emotion and cognition. Language, as a means of communicating and studying in human society, is one of the vital cognitive activities of human beings (Chen \& Zhang, 2017). Therefore, the relationship between emotion and language learning is valued by researchers all over the world. As an important stimulant and organizer of cognition, action, social communication and development, emotion plays an important role in language processing and language learning (Liu, Hu, \& Peng, 2009). The study on the relationship between emotion and language processing can help teachers improve their teaching efficiency and improve the students' language learning efficiency, especially for the children's language teaching and learning (Dong, 2017).

ZHANG Shu-ya, Postgraduate Student, School of Foreign Languages, Wuhan University of Technology, Wuhan, China. 
According to the Interaction Theory, this paper uses observational method to observe the listeners' reactions to Ivanka Trump’s public speech, My Father Is a Fighter, including the applause, yell, face expression, and action, to study the influence of emotion on language processing and to study the teaching methods which can motivate students' interests in learning and improve their language learning efficiency. The study on Ivanka's sheech is mainly from two aspects: (1) the influence of emotional information in language on language learning, including emotional words and sentences; (2) the influence of external emotional background on language learning, including the emotional intonation, speech rhythm, and emotional context.

The study about the influence of emotion on language learning in a case study of Ivanka's public speech has vital significance in teaching and learning. Academic speeches which are very scientific and informative have the logic of argumentation and the penetration of knowledge (Sun, 1995). Therefore, the academic speeches tend to form a deep and steady style with gentle intonation and rarely body language with the purpose of teaching knowledge (Sun, 1995). However, the public speeches which can influence the listeners' decision are powerful with emotional intonation and many body languages with the purpose of persuading (Wang \& Cheng, 2007). Although academic speeches differ from public speeches in terms of content and purpose, applying the speech method of public speech to academic speech has vital significance in motivating students' learning interests and improving their learning efficiency. As we all know, there is low participation in both primary and university classrooms because of the monotonous classroom atmosphere, difficult classroom content, and other reasons (Dong, 2017). It means that many students have low learning efficiency. Therefore, the method to draw the attention of students and motivate students' learning interests has vital effect on teaching and learning. This paper tends to study a kind of teaching methods which can apply the advantages of public speech skills to the academic speech in order to help teachers improve the students' teaching efficiency.

\section{Influence of Emotional Information in Language on Language Learning}

Language can not only express the conceptual information, but also express the emotional information. Researches have shown that the emotional information in language has vital influence on language processing and language learning (Liu, Hu, \& Peng, 2009). The emotional information on language studied in this paper includes emotional words and emotional sentences.

In public speeches, the listeners' applause is not only a kind of praise but also a kind of external reaction of their language learning. The author finds that in Ivanka's 12-minute speech, there is much tumultuous applause, a total of 25 times. Among them, over 70 percent of applause appeared after Ivanka said the emotional words, such as great, excellence, better, etc., and emotional sentences, such as "My father is a fighter". However, when she said the descriptive sentences about her father, for example, "When my father says he will build a tower, keep an eye on the skyline. Floor by floor, a soaring structure will appear, usually record-setting in its height and iconic in its design”, the listeners just listened to her speech quietly without any obvious action. However, when she said the emotional sentence about her father, for example, "He will fight for equal work, and I will fight for this too, right alongside of him", the listeners burst into applause, and most of the listeners stood up, yelling: "Trump, Trump, Trump...” These two different types of sentences have the same aim, namely, admiring her father. However, the listeners have total different reactions to these two types of sentences. This phenomenon demonstrates that emotional information in language has great influence on people's language processing and 
language learning. Using more emotional words or emotional sentences can arouse the resonance of the listeners more easily.

Therefore, if the teacher can apply this method to academic speech, namely, giving the academic speech in class with more emotional words or sentences just like Ivanka did rather than the simple descriptive sentences which include a lot of boring information, the students will have more interests in the content of teacher's speech with more positive reactions. The application of this finding in children language teaching and learning is showed in part four.

\section{Influence of External Emotional Background on Language Learning}

People are always in a certain emotional background and will be affected by their emotional state all the time (Liu, Hu, \& Peng, 2009). People will be affected by the external emotional background. So the study on this phenomenon can help the teacher keep their students in a positive state which is helpful to the students' learning efficiency. The external emotional background studied in this paper is mainly the emotional intonation and speech rhythm.

In Ivanka’s public speech, she speaks smoothly with almost no mistake (Yan, 2017). Her pronunciation is standard and clear with good speech rhythm and emotional intonation which can help her listeners listen carefully and evoke the listeners' interest. She smiles during the whole speech and pays attention to leave enough time for applause. From the face expression of smiling and the action of standing up, we can see the great influence of Ivanka's emotional intonation and good speech rhythm on the listeners. What's more, in Ivanka's speech, there are three extraordinary applause with the yell of "Trump, Trump, Trump...” All of the three applause appeared after Ivanka spoke with highlighted emotional intonation. And most of the listeners smiled and stood up to clap. Ivanka Trump successfully helps her father get more votes in the American presidential election by her public speech My Father Is a Fighter. She creates the emotional background for her listeners with using emotional intonation and giving the speech with speech rhythm. It means that emotional intonation and good speech rhythm can draw the attention of the listeners and it can also influence the thoughts and actions of the listeners. If teachers can apply these techniques to their academic speeches, their courses will be more attractive.

A big difference between public speech and academic speech is the intonation, therefore, if teachers can apply these techniques of public speech to academic speech, namely, speaking something with good speech rhythm and emotional intonation rather than the monotonous intonation which is just like a robot, the students will listen to the academic speech with more positive attitude. As a result, the students can improve their learning efficiency and learn more knowledge in class. The application of this finding in children language teaching and learning is showed in part four.

\section{Application in Language Teaching and Learning for Children}

According to the study about Ivanka Trump's public speech My Father Is a Fighter in this paper, we can see the important influence of emotion on language processing and language learning, including the emotional information in language, namely, emotional words, sentences, and speeches and the external emotional background on language learning, namely, the emotional intonation, speech rhythm, context, and so on. Due to the children's uniqueness, kindergarten teachers need to pay more attention to children's emotion and interest 
when teaching children knowledge (Wang, 2019). So if kindergarten teachers can apply the speech methods of public speech to teaching, for example, using more emotional words and sentences, speaking with emotional intonation and so on, their courses will be more interesting and attractive. What's more, the children can also improve the learning efficiency in the attractive courses. The author uses one year to study the influence of emotion on children language learning with applying the public speech methods on the academic speech in class. The findings are as follows.

\section{Using More Emotional Words and Sentences}

Children's learning is more easily influenced by feelings and emotion. Without good emotion, they can’t pay attention to the language that their teacher said. They will cry or do other unbelievable things. So the teachers need to do something which is related to the teaching so as to draw the students' attention. Using more emotional words and sentences in class is a good method to draw children's attention. Application 1 of using more emotional words and sentences is in the process of describing the teaching content. After a year of experimentation, the author finds something useful. For example, when teaching the word "butterfly", the teacher can say: "Wow, what is this? It is so beautiful. It can fly. And it is colorful. I like it so much. Do you know it?" The emotional words "beautiful”, "like”, and "so much" can arouse children’s interests easily. They will be curious about the things that their teacher described. Application 2 of using more emotional words and sentences is to encourage children. When a child did a good job, the teacher can say “Good!”, “Great!”, “Excellent!”, or other emotional sentences. These words or sentences can motivate the children and improve their self-confidence which can evoke children's interest in learning language. It can make their learning more interesting and easy.

Application 3 of using more emotional words and sentences is to let the naughty students calm down. As a teacher in an English training institution, the author use one year to study the influence of positive emotional words like “Good!”, “Great!”, “Excellent!”, and emotional sentences on a seven-year-old boy who is naughty and splenetic. At the beginning, this boy often disturbs the class and talks back to the author, because he often fails paying attention to the author's class. With time goes by, the author finds that when the author says: "Wow, Tim, you are so great. I believe that you can do a better job. Come on, baby", this boy will begin to calm down and he will be quiet and shy. What's more, he will listen to the teacher's academic speech carefully and answer teacher's questions actively. As a result, it improves this boy's learning efficiency. On the contrary, if the author says some negative emotional words or sentences, for example, “Oh, Tim, you are a bad boy. We all don't like you”, this boy will be naughtier and he will do something unbelievable. For example, he will go out of his seat, walk in the classroom, and start shouting in the class. This phenomenon shows that using more positive emotional words or sentences can help teachers keep discipline in the class and improve the teaching efficiency. What's more, it can draw children's attention and improve their learning efficiency.

\section{Creating Emotional Background}

People are always in a certain emotional background and will be affected by their emotional state all the time (Liu, Hu, \& Peng, 2009). This emotional background includes people's emotional state and the external emotional background, such as, the music, the emotional intonation, the emotional context, and so on. To study the influence of emotional background on children, the author creates positive emotional background when teaching children in the class. 
Application 1 of creating positive emotional background is to play some happy music when the children is tired or bored in the class. And the author has done some experiments during the teaching process of one year. In the class, when the children are tired or bored, the author will play some happy music and dance with the children. Then the children will be very happy and they will be active again. This result shows that music can help children keep a happy state which is helpful to their study.

Application 2 of creating positive emotional background is to create some emotional content when teaching in the class. And the author also did some experiments during the one-year teaching process. The author compares two different teaching approaches: One is the traditional teaching method, namely, the teachers give the academic speech with monotonous intonation which is just like a robot and the students just listen to the academic speech quietly; the other is the situational approach, namely, creating some emotional content and in this situation, the students can study at some emotional state. For the traditional teaching method, the children have to learn the course content with the teacher's force. Actually, if there isn't the exam, they will not want to listen to the teacher's academic speech. This has been been confirmed by the author's experiment. However, when the author uses the situational approach to teach, the children become very happy. Compared with the traditional teaching method, this teaching method can help the children have more interests in the teachers' course content. The children will learn the knowledge actively and recite the sentences to play the role in the certain situation. For example, in the experiment course of "Shops", the author divide the students into two groups, one group selling things, the other buying things. Then the author teach them some related sentences and let them recite to play. As a result, the author finds that the situational approach is more attractive, and the students can also learn the useful knowledge spontaneously in this relaxing situation which achieves that children can learn knowledge in the game.

\section{Conclusion}

Emotion has vital influence on language processing and language learning in the aspects of emotional information in language and external emotional background. The study about the influence of emotion on language processing and language learning in a case study of Ivanka's My Father is a Fighter has vital significance in teaching and learning, especially for children language teaching and learning. Because of the scientific and informative features of the academic speeches, they have the logic of argumentation and the penetration of knowledge. Therefore, the academic speech is in a deep and steady style with gentle intonation and rarely body language with the purpose of teaching students knowledge. However, the public speeches which can influence the listeners' decision are powerful with emotional intonation and many body languages with the purpose of persuading. The academic speeches are different from the public speeches in terms of content and purpose.

This study shows that the speech with more emotional words or sentences and emotional intonation rather than the simple descriptive sentences or monotonous intonation can influence people's language learning and draw the people's attention more effectively. Although academic speech is different from public speech, the teachers can also apply the dramatic speech methods of public speech which can motivate the listeners' interests to the academic speech, namely, using more emotional words or sentences, emotional intonation and creating emotional background to modulate students' language learning so as to improve their learning efficiency. 
Applying the speech methods of public speeches to the academic speeches has vital significance in motivating students' learning interests and improving their learning efficiency.

\section{References}

Chen, X. K., \& Zhang, J. J. (2017). The role of language in emotional theory: A conceptual behavioral model from basic emotional view to psychological construction view. Journal of Northwest Normal University (Social Science Edition), 54(3), 132-137. (In Chinese)

Dong, Q. (2017). Research on the application of psycholinguistic principles in college english teaching. Journal of Suzhou Education College, 20(1), 116-157. (In Chinese)

Huan, H. R. (2015). The operating patterns of learner emotion in second language learning. International Research Association of Information and Computer Science, 3, 621-623.

Ivanka Trump's speech to the Republican National Convention. (n.d.). Retrieved from https://wenku.baidu.com/view/c1c4e65e32687e21af45b307e87101f69e31fbf5.html

Liu, H. Y., Hu, Z. G., \& Peng, D. L. (2009). The interaction between emotion and language processing. Progress in Psychological Science, 17(4), 714-721. (In Chinese)

Sun, G. G. (1995). On speech and teaching. Heilongjiang Higher Education Research, (3), 47-49. (In Chinese)

Wang, H. Y., \& Cheng, C. S. (2007). A comparative study of the modality of english political speeches and academic speeches. Foreign Language and Foreign Language Teaching, (5), 21-24. (In Chinese)

Wang, L. P. (2019). Study on negative emotional adjustment in the teaching of english for primary schools. Reading and Writing (Educational Teaching Journal), 16(1), 185-229.

Yan, H. (2017). Comment on Ivanka Trump’s speech. Journalism Research Guide, 8(19), 285. (In Chinese) 